\title{
Reformation als Motiv auf Bucheinbänden
}

\section{Text und Bild}

Die Reformation stellte das Wort Gottes als Grundlage des Glaubens neu heraus' ${ }^{1}$. Doch wusste Luther auch um die Bedeutung des Bildes. Das Bild hatte den Vorteil, Inhalte nicht nur intellektuell-verbal, sondern sinnlich-ganzheitlich zu vermitteln. Im Bild konnten mehrere Inhaltsaspekte gleichzeitig zum Ausdruck gebracht werden. Das Bild konnte zuspitzen oder bestimmte Einzelinhalte betonen.

Die Illustrationspraxis bezog sich auch auf die individuelle Gestaltung der Bucheinbände. Bereits die Tatsache der Verzierung des Einbandes sollte eine Wertschätzung des Inhalts oder auch Zwecks des jeweiligen Buches zum Ausdruck bringen. Allerdings verrät die Motivik des Einbanddekors einiges über die Wertempfindungen und geistigen Orientierungen einer Epoche.
Der lebendige Geist Luthers wird aus den Schriften erkannt, von daher das Bild). Auf dem Rückdeckel sieht man Luthers engsten Mitarbeiter Philipp Melanchthon. Zu inm heißt es: „Forma Quidam Potis Est Sed Mens Tua Nesci Pingi" (etwa: Ein Bild vermag gewissermaßen zu malen, dein Geist weiß es nicht). Zusammengenommen bedeutet dies: Um die Reformatoren wirklich zu verstehen, muss man ihre Schriften lesen. Erst von dorther wird auch die bildliche Darstellung verständlich. Andererseits kann das Bild bestimmte Eigenschaften oder Aspekte hervorheben und veranschaulichen, die dem menschlichen Geist aus sich heraus nicht ohne weiteres auffielen. Das Bild macht also etwas konkret und präzise, was sonst gedanklich im Vagen bliebe. ${ }^{2}$

\section{Werkzeuge, Komposition, Statistik}

Die Prägung des Lederbezugs erfolgte sukzessive, weil stets mehrere Werkzeuge zum Einsatz kamen bzw. dasselbe Werkzeug mehrfach Verwendung fand. Die inhaltlichen Bezüge ergaben sich aus den Motiven der Einzelwerkzeuge und aus der Kombination der Werkzeuge auf dem Einband.

Charakteristisch für Renaissance-Einbände ist der intensive Einsatz von Rollen und Platten. Dabei nahm der Anteil figürlicher Motive gegenüber ornamentalen zu. Dies war auch eine Folge der Wertschätzung des Individuums mit seinen spezifischen Eigenschaften und Fähigkeiten. Der Zugewinn an Platz zur . Luther und Melanchthon als Durchreibungen (Ba lat.1602 01)
Gestaltung von Motiven bei den Rollen und Platten gegenüber den meist kleinen Einzelstempeln erlaubte die Kombination mehrerer bildlicher Szenen und vor allem die Hinzufügung textlicher Bausteine zur Präzision. Der Zusammenhang von Wort und Bild entsteht hier nicht nur durch das Zueinander von Einband und Buch, sondern durch die Gestal-

1) Gekürzte Fassung eines Vortrags für die Württembergische Bibliotheksgesellschaft am 21.3.2017.

2) Luther-Bildnis-Platten wurden häufig auch mit einem in ähnliche Richtung zielenden Textzusatz versehen: "Nosse cupies faciem Lutheri hanc cerne tabellam si mentem libros consule certus eris" (Du willst das Angesicht Luthers erkennen, schaue auf diese Bildtafel. Wenn du den Geist erkennen willst, ziehe die Bücher zu Rate, du wirst sicher sein) (z.B. Bb lat.1523 01) 
tung des Verzierungswerkzeuges selbst.

Quantitative Beobachtungen mit Hilfe der Einbanddatenbank ${ }^{3}$ lassen den Schluss auf Verschiebungen in der Popularität bestimmter Motive zu. Maria spielt z.B. eine wichtigere Rolle in der vorreformatorischen bzw. katholischen Frömmigkeit als in der theologischen Tradition der Reformation. Das quantitative Verhältnis von Marien- und Christusdarstellungen sagt etwas aus über die Struktur der jeweiligen Frömmigkeit:

- Gotische Einzelstempel: Maria: 144. Christus: 186

- Platten: Maria: 64. Christus allgemein: 174. Kreuzigung: 132. Auferstehung Christi: 81. Taufe Christi: 46. Geburt Christi: 37

- Rollen: Maria: 92. Christus allgemein: 318. Kreuzigung: 108. Auferstehung Christi: 120. Taufe Christi: 42. Geburt Christi: 3

- Luther: 55 Platten. 84 Rollen (außerdem 59 mit Reformatorenköpfen allgemein)

Person und Wirken Christi gewinnen im 16. Jahrhundert an Gewicht. Maria und allgemein die vermittelnden Instanzen zwischen Gott und dem Individuum verlieren an Akzeptanz. Das deutet auf die zumindest teilweise Durchsetzung reformatorischer Theologie mit der Betonung der Unmittelbarkeit der Beziehung zwischen Gott und dem Menschen bzw. mit der Zentrierung auf Christus hin. Das Individuum gewann an Bedeutung, auch die figürliche Darstellungsweise abstrakter Gedanken. Wie die große Zahl der Lutherdrucke insbesondere im Zeitraum zwischen 1520 und 1550, so deutet die Zahl der Einbandwerkzeuge mit Lutherbildnissen auf Veränderungen in den herrschenden geistesgeschichtlichen Strömungen hin.

\section{Direkte motivische Rezeption der Reformation: Reformatoren-Bildnisse}

\section{Rollen}

Die Motive der Rollen sollten buchtechnisch, gelegentlich auch inhaltlich den Rahmen bilden, innerhalb dessen die im Mittelfeld dargestellten Inhalte bedeutsam wurden. Häufig wurden Köpfe in Medaillons, meist mit den Namen der dargestellten Personen bzw. deren Kurzform, auf den Einband geprägt. Am häufigsten findet man eine Vierergruppe mit Martin Luther, Philipp Melanchthon, Erasmus von Rotterdam und Jan Hus. Die drei zuerst genannten Personen waren im deutschen Sprachraum die bekanntesten Namen des 16. Jahrhunderts und wiesen die höchste Zahl an Publikationen auf. Bemerkenswert ist das, weil es ab 1525 zu heftigen Auseinandersetzungen zwischen Luther und Erasmus und nach 1560 zwischen den strikteren Schülern Luthers und den Anhängern Melanchthons kam. Dezidiert katholische Personen wie Päpste oder zeitgenössische Bischöfe wurden hingegen auf den Rollen nicht abgebildet und zwar auch nicht in den katholisch gebliebenen Gebieten und deren Buchbinderwerkstätten. Man kann bei der Kombination Luther, Melanchthon, Erasmus davon ausgehen, dass sie zunächst stellvertre-

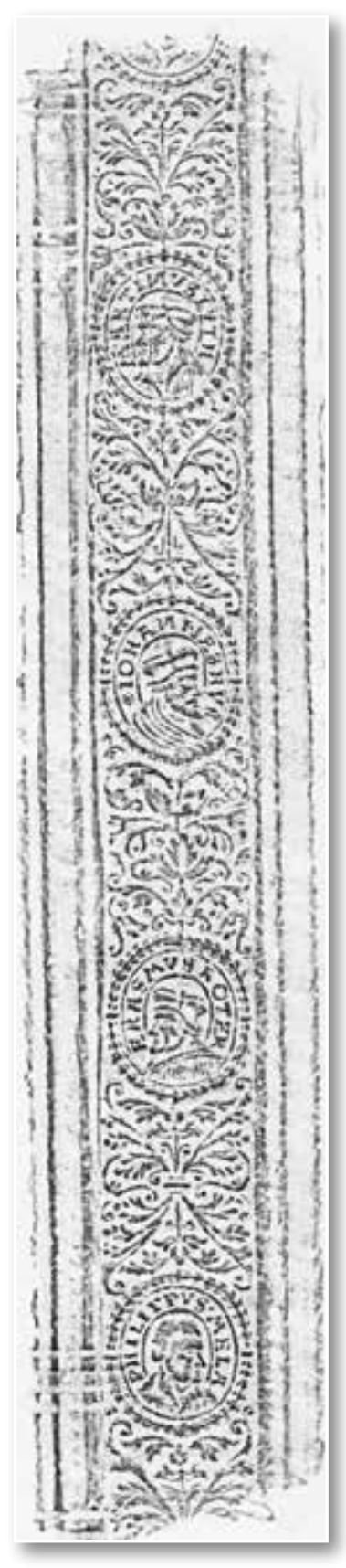

Abb. 3: Vierergruppe auf Rolle (Theol.fol.233-4)

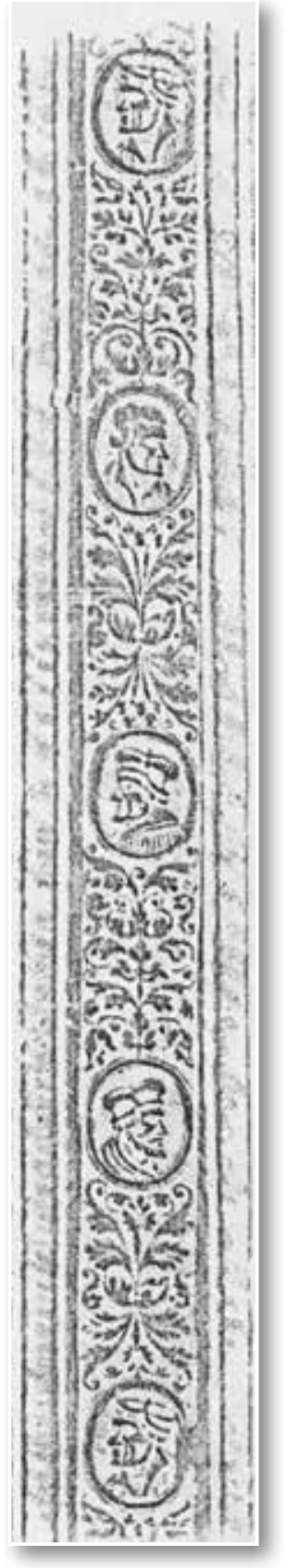

Abb. 4: Reformatorenköpfe ohne Namen (Werkstatt H. V. M.) 
tend für die Geistesgrößen der Zeit verwendet wurden. Sie sollten den Gegenwartsbezug und die Aktualität der Kunst verdeutlichen. Allerdings zeigte die Verknüpfung mit Jan Hus (1369-1415) in vielen Rollen, dass auch eine theologische Botschaft impliziert war. Jan Hus brachte einige ähnliche Reformvorschläge wie Luther vor, allerdings über hundert Jahre früher. Hus ist auch sonst in Gestalt eines Schwans ein ikonographisches Attribut Luthers. Damit bezogen sich die Künstler auf ein Zitat von 1531, in dem sich Luther als von Jan Hus (Hus, tschechisch = Gans) prophezeiten Vollender der begonnenen Kirchenreform verstand: „Johannes Hus hat von mir geweissagt, ... Sie werden itzt eine gans braten (denn Hus heisst eine gans) Aber vber hundert iaren, werden sie einen schwanen singen horen, Den sollen sie leiden" (WA 30/ III, S. 387b). Indem die von Hus ausgesprochene Verheißung als in Luther erfüllt herausgestellt und Hus und Luther ikonographisch verbunden wurden, ging es um Apologetik der Reformation. Deren Rechtgläubigkeit sollte durch das Eintreffen der Verheißung unterstrichen werden. Auch Erasmus erscheint im Gespann mit Luther so in einem anderen Licht. Die Anliegen des Humanismus fanden nach dem Selbstverständnis Luthers in der Reformation ihre Erfüllung und Korrektur zugleich. Man denke hier an die exakte philologische Arbeit, die Betonung des Literalsinns der Bibel und die Bedeutung des Individuums in der Gottesbeziehung.

Eine Rolle mit Köpfen, die hinsichtlich Kleidung und Haltung dem Stil der Reformatoren-Abbildungen entsprachen, war auch gängig im katholischen Kontext. Es handelte sich sozusagen um ein künstlerisches Genre, auf das man nicht verzichten wollte. Im Nachlass von Ernst Kyriss findet man eine Durchreibung aus dem Werkzeugreservoir des Buchbinders (H. V. M.), der für den katholischen Theologen Erasmus Neustetter (1523-1594) arbeitete. Die Rolle verzichtete bewusst auf die Namen der dargestellten Personen. ${ }^{4}$ Diese stehen allgemein für Gelehrsamkeit und theologische Ernsthaftigkeit.

\section{Platten}

Platten erlaubten eine für die Bedingungen der Einbandverzierung relativ großformatige Präsentation bildlicher Motive. Die Drucker und Buchbinder des 16. Jahrhunderts wussten darum, dass emotionale Bindung und Identifikation mit inhaltichen Anliegen und den sie vertretenden Bewegungen sich gerade an Personen festmacht. Luther stellte das bekannteste Gesicht der Reformation dar. Im Mittelalter wäre es noch undenkbar gewesen, das gesamte Lehrsystem auf eine historische Person zu fokussieren und diese künstlerisch herauszustellen. Außerbiblische Personen bzw. Personen der jeweiligen Gegenwart wurden zumindest in oder auf Bibeln nicht dargestellt, um die Gedanken der Betrachter nicht zu sehr an den Bereich des Irdischen zu binden. Nun aber gab es eine Person, deren Name zum Synonym für einen theologischen Ansatz bzw. für ein kirchliches Reformprogramm geworden war.
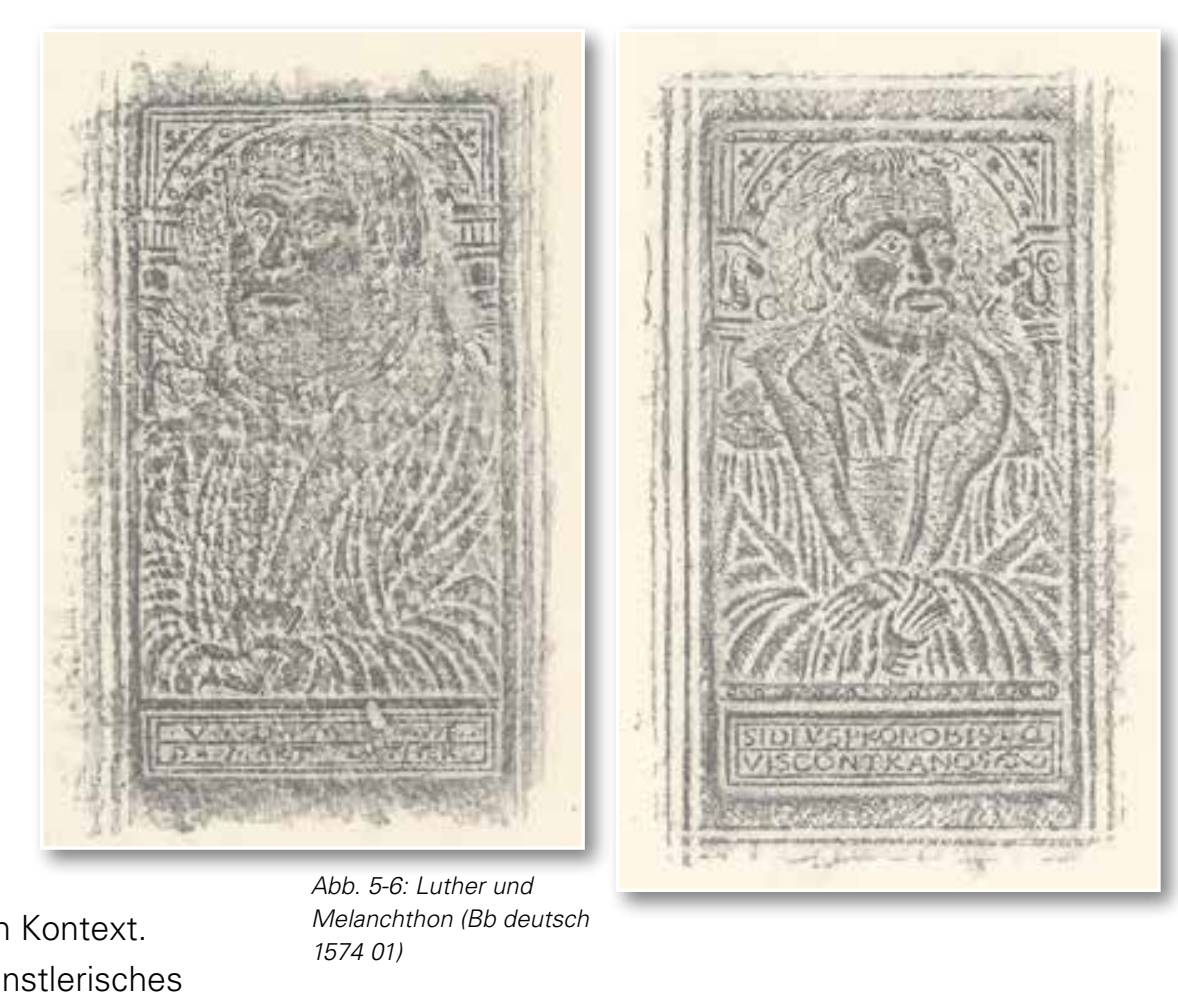

Melanchthon (Bb deutsch 57401

Auf Einbänden wurde Luther häufig mit Melanchthon kombiniert. Luther erschien als der wichtigere Reformator in der Regel auf dem Vorderdeckel, Melanchthon auf dem Rückdeckel. Luther wurde meistens - ikonographisch typisch - als der Wichtigere nach rechts gewendet, Melanchthon nach links. Beide hatten die Bibel in der Hand. Die Bibel war für reformatorische Theologie die zentrale Erkenntnisgrundlage. 
Meistens wurde mit der bildlichen Darstellung ein Textzusatz verbunden, nämlich ein authentisches Motto der dargestellten Person oder komprimierte Hinweise des Künstlers. Die Textzusätze der Reformatoren-Bildnisse an einer Frankfurter Lutherbibel von 1574 (Bb deutsch 1574 01) deuteten eine zentrale Erkenntnis der Reformation an: Durch die Ausrichtung auf Gott und sein Wort entsteht und besteht Gewissheit. Gott und sein Wort wird sich demnach beim Einzelnen wie auch insgesamt gegen Widerstände durchsetzen und Bestand haben. Bei Luther war es das Motto der Reformation allgemein, hier in abgekürzter Form: VDMIE: Verbum Domini manet in aeternum / Das Wort Gottes bleibt in Ewigkeit. Bei Melanchthon handelte es sich um eine Anspielung auf Römer 8,31: Si Deus pro nobis quis contra nos? / Ist Gott für uns, wer kann wider uns sein?

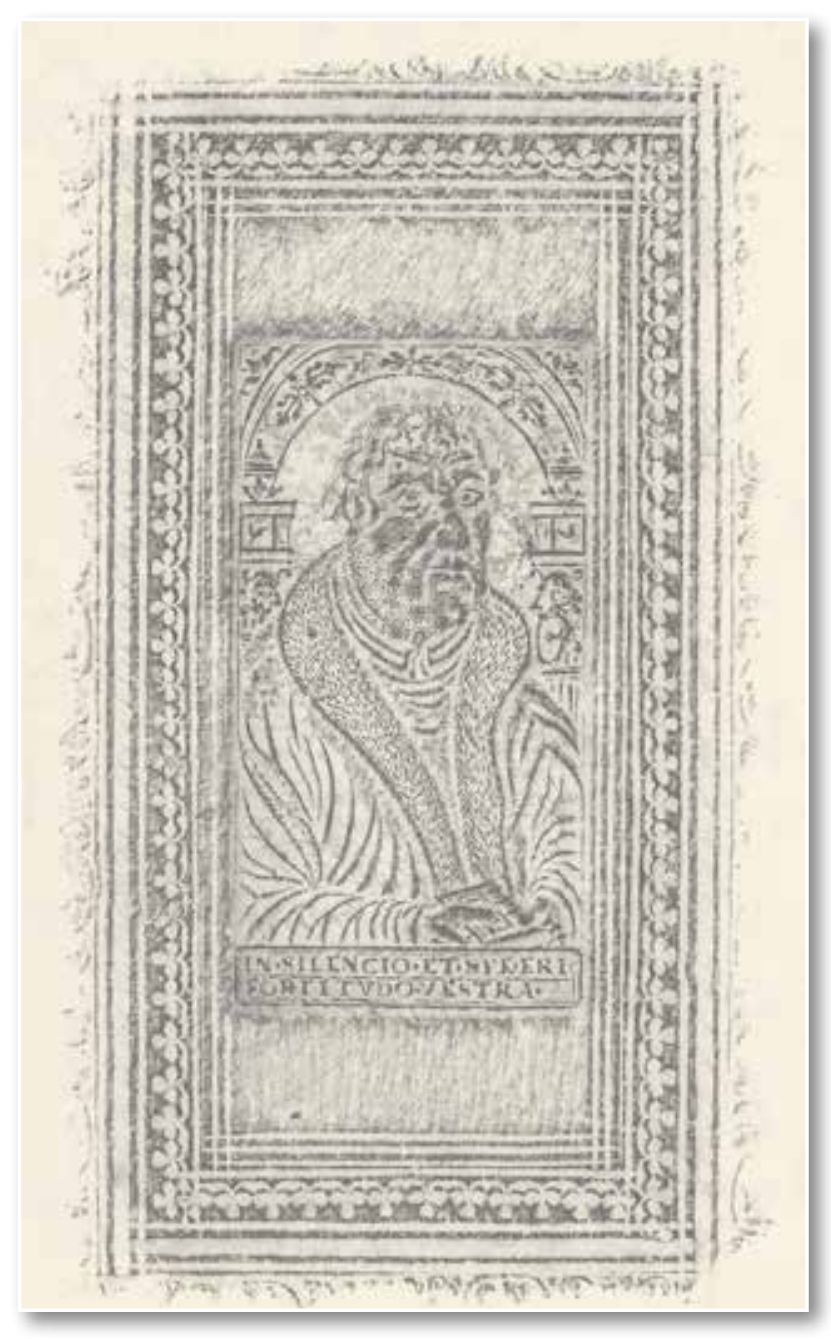

Abb. 7: Luther-Bildnis mit Motto (Bb lat.1643 01)

Bei den Motti gab es Varianten. So wurde zu einem Luther-Bildnis häufig ein modifiziertes Zitat aus Jesaja 30,15 ergänzt: „In silencio et spe erit fortitudo vestra" (z.B. Bb lat.1643 01). Luther übersetzte in der Ausgabe letzter Hand (1545): "Durch stille sein vnd hoffen wuerdet jr starck sein". Es geht also erstens darum, von sich weg auf einen außerhalb seiner selbst liegenden Bezugspunkt zu sehen, sich zurückzunehmen, zu empfangen. Zweitens handelt es sich bei dem externen Bezugspunkt nicht um ein neutrales Etwas, sondern um Gott als personales Gegenüber. Daraus entstehen die Gewissheit in der Hoffnung sowie die Stärke, die verliehen, nicht erarbeitet ist. Dieses "extra nos" (außerhalb von uns) markiert den Kern der reformatorischen Entdeckung Luthers und passt daher gut als Motto. Das Zitat ist zugleich auf die Zukunft ausgerichtet und sollte durch die künstlerische Vergegenwärtigung den Anhängern der Reformation Mut machen.

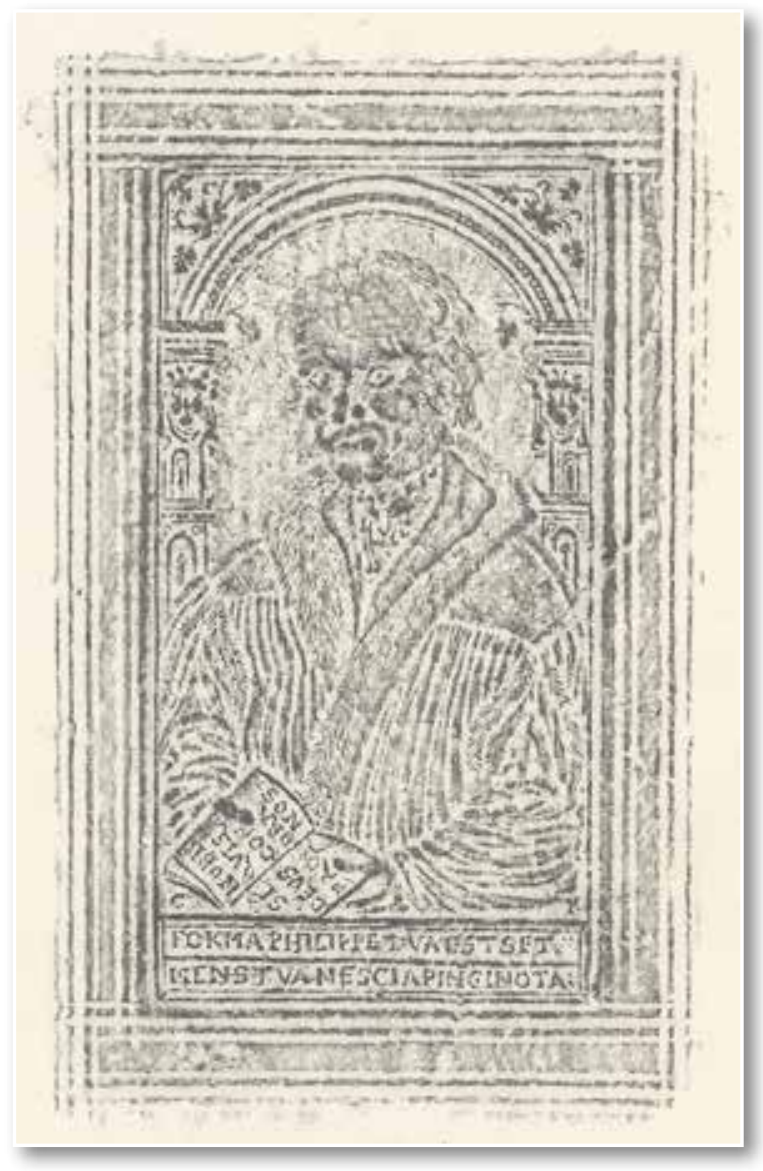

Abb. 8: Melanchthon mit doppeltem Motto (B lat.1567 09)

An einer 1567 in Lyon gedruckten lateinischen Vulgata (B lat.1567 09) begegnet eine Kombination der Bildnisse Luthers und Melanchthons mit jeweils zwei Motti. Auf der aufgeschlagenen Bibel kann man bei Luther lesen: „Verbum Domini manet in eternum". Auf dem Spruchband darunter steht: "In Silencio et Spe Erit Fortitvdo vestra Martini Luder". 
Bei Melanchthon liest man in etwas fehlerhaftem Latein die Wahlsprüche "Si Devus pro nobis quis contra nos" bzw. "Forma Philippe Tua es Set Mens Tua Nescia Pingi Nota". Gemeinsam ist den ersten drei der hier aufgeführten Motti das Vertrauen auf die letztendliche Durchsetzung Gottes bzw. seines Wortes gegenüber Anfechtungen und Widerständen unterschiedlichster Art.
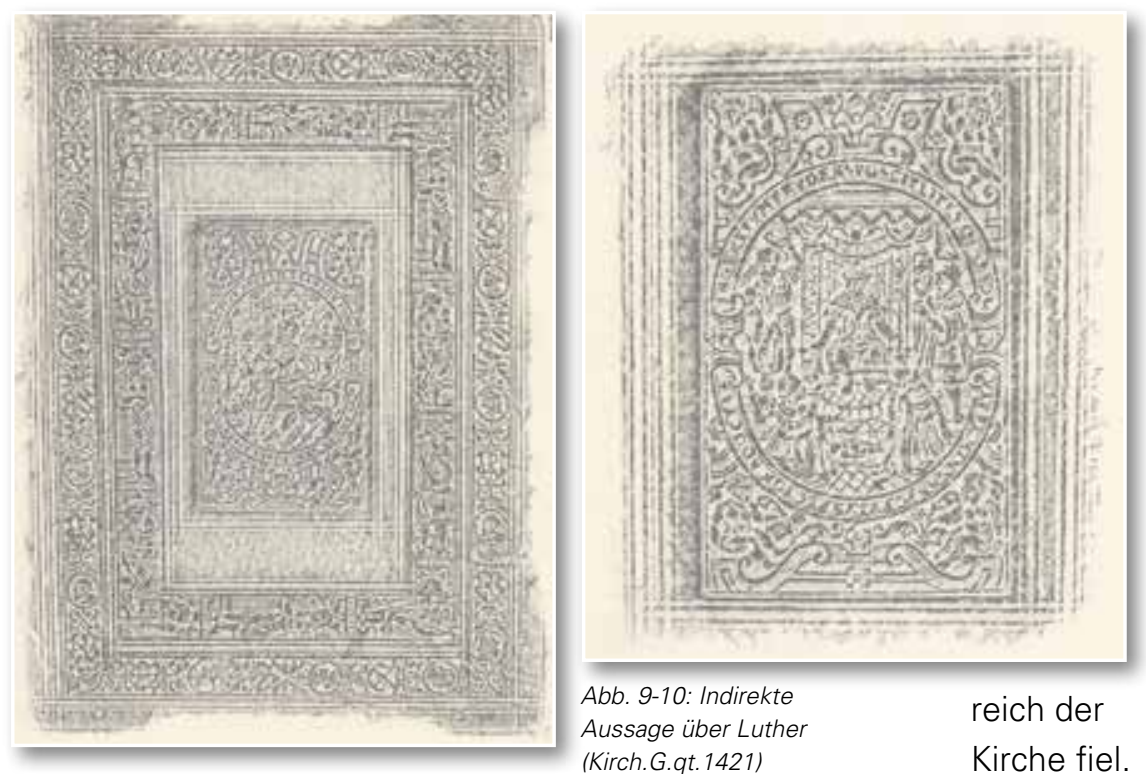

Abb. 9-10: Indirekte Aussage über Luther (Kirch.G.qt.1421)

Viele Lutherbildnisse sollten durch Kleidung, Gestik und Körperhaltung bzw. Attribute wie die Bibel den Eindruck von Gelehrsamkeit, Entschlossenheit und Frömmigkeit vermitteln. Dies konnte aber auch indirekt durch die Kombination anderer Motive mit entsprechenden Textzusätzen geschehen. So wurde eine Ausgabe der bekannten LutherBiographie des Johann Mathesius, Nürnberg 1588 (Kirch.G.qt.1421), mit zwei Platten zu biblischen Erzählungen dekoriert. Auf dem Vorderdeckel wurde Simson dargestellt mit der Szene, in der er einen Löwen mit bloßen Händen zerreißt (Richter 14,6). ${ }^{5}$ Dieses Verhalten steht für Mut und Entschlossenheit, aber auch Gottvertrauen. Auf dem Rückdeckel wurde das Salomonische Urteil dargestellt (1. Könige 3,16-28). ${ }^{6}$ Salomo wurde dadurch zum Inbegriff der Weisheit.

Zweibändige Werke boten die Möglichkeit doppelter Kombinationen. So verzierte Lucas Weischner aus Braunschweig jeweils den Vorderdeckel einer zweibändigen Wittenberger Lutherbibel (Bb deutsch 1581 02) mit einem Luther-Bildnis und verknüpfte dieses mit einer Kreuzigungs- bzw. Auferstehungs-

reich der
Kirche fiel. grenzte die staatliche Aktivität. Die Unterscheidung von Staat und Kirche bedeutete nicht, dass die Herrüber Gott. szene auf den Rückdeckeln. Die biblischen Zitate in den Textzusätzen sollten die von Luther betonte Erlösung aus der Macht von Sünde und Tod andeuten.

\section{Indirekte motivische Rezeption der Reformati- on: Herrscher-Bildnisse} profaner Herrscher gehört zu den Konsequenzen der Reformation. Luther stellte die Funktion weltlicher Herrscher im Rahmen des Erhaltungshandelns Gottes heraus. Er unterschied zwischen einerseits der Politik, bei der es um die Eindämmung des Bösen und die Gestaltung des kreatürlich Möglichen gehen konnte, und andererseits der Erlösung, die in den Kompetenzbe-

Dies entlastete und be-

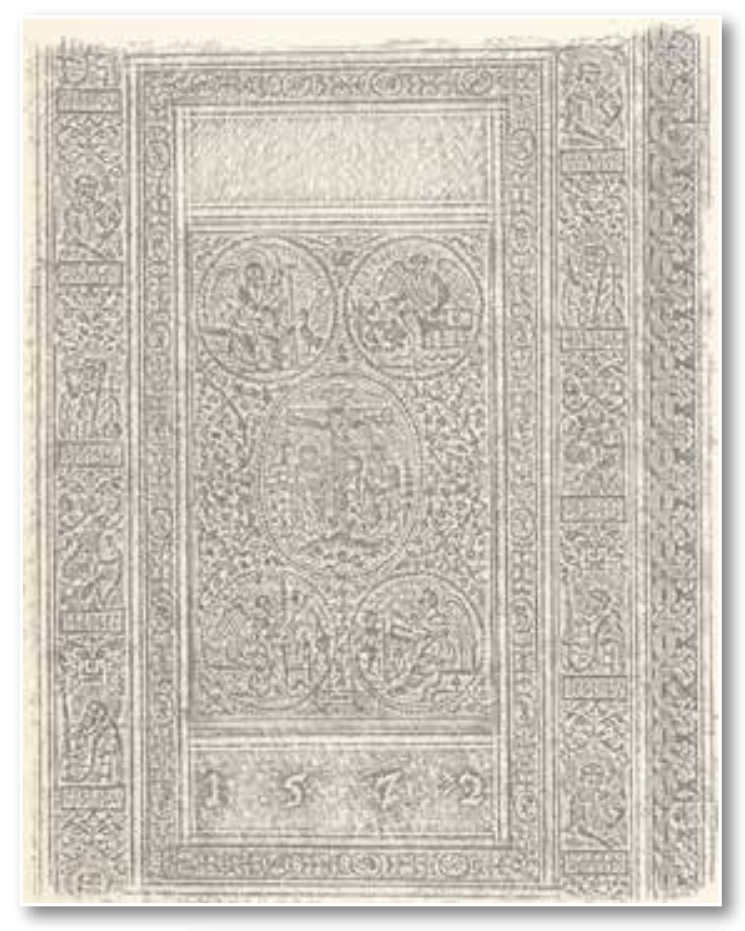
scher ihre Macht rein säkular zu verstehen hatten. Vielmehr sollten sie sich verantwortlich sehen gegen-

\section{Dementsprechend nutzten die Herrscher und die in ihrem Ein- flussbereich stehen- den Buchbinder die Kunst zur Darstellung}

Die positive Würdigung staatlichen Handelns und

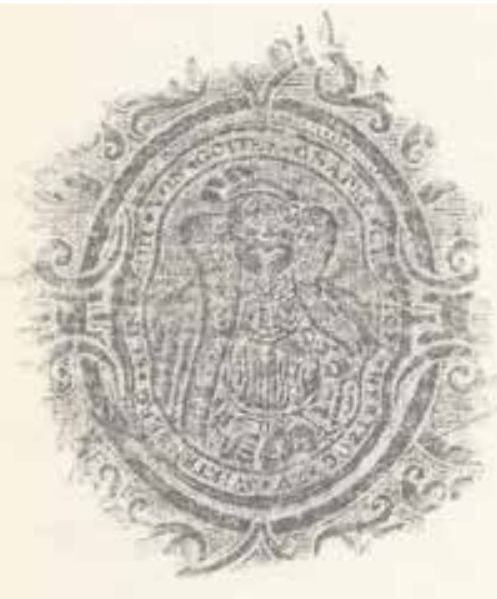

Abb. 11-12: Herzog Christoph und Theologie (Bb griech.1565 01)
5) Textzusatz dazu: NASCITVR ANGELICO SAMSON CONCEP / TVS AB ORE VRBE FORES AVFER SAMSON.

6) Textzusatz dazu: INGENITVM PRVDENS POSCIT LITESQ RESOL / VIT FEMINEAS POPVLVS PECTORA DOCTA. 
ihres Selbstverständnisses im Sinne der Reformation. Auf den Vorderdeckel eines griechischen Neuen Testaments (Bb griech.1565 01) wurde eine Kreuzigungsszene in Verbindung mit Evangelistensymbolen aufgeprägt. Der Rückdeckel präsentiert Herzog Christoph von Württemberg. Zusammengenommen wurde angedeutet: Dieser Herrscher sieht sich im Sinne der Reformation der Heiligen Schrift (Evangelistensymbole) und zwar in ihrer Zuspitzung auf Jesus Christus als Erlöser verpflichtet. Wie kein anderer Herrscher nach ihm gestaltete Herzog Christoph sein Land zu einem dezidiert lutherischen Staatswesen um.

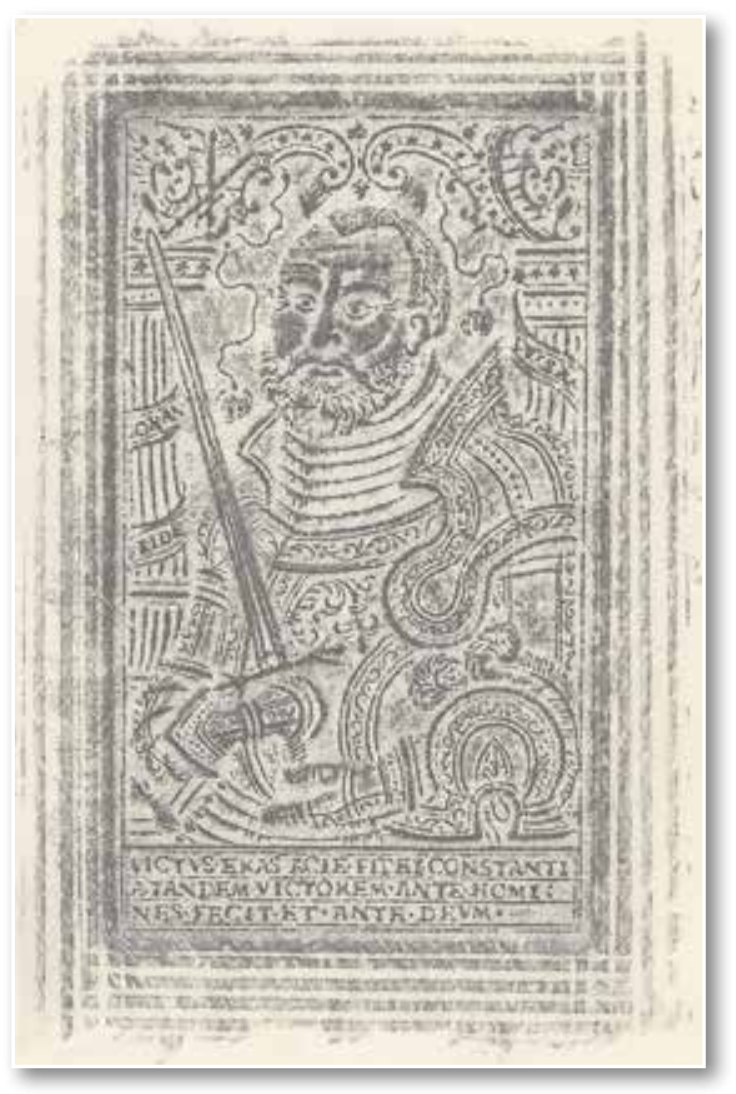

Abb. 13: Herzog Johann Friedrich I. von Sachsen (Kirch.G.fol.266)

Die Ernestiner als Landesherren Luthers sahen sich der Reformation und ihrem geistigen Erbe besonders verbunden. Sie gehörten zu den Hauptverlierern des Schmalkaldischen Kriegs (1546-1547). Nach der Schlacht von Mühlberg 1547 wurde der damals amtierende ernestinische Herrscher Johann Friedrich I. von Sachsen (15031554) gefangen genommen, verlor seine Kurwürde und einen Großteil seines Territoriums sowie die Universität Wittenberg an die rivalisierenden Albertiner. Trotzdem blieb er standhaft, verweigerte die Wiedereinführung des katholischen Ritus und gründete als Ersatz für Wittenberg die Universität
Jena, die dann eine Bastion des streng konfessionellen Luthertums werden sollte. Auf diese Rolle Johann Friedrichs spielte eine Porträtplatte an, die das Konterfei des Fürsten mit einem passenden Textzusatz ergänzte: Zusatz: „Victus Eras Acie Fidei Constantia Tandem Victorem Ante Homines Fecit Et Ante Deum" (du warst zwar besiegt durch die Schärfe [des Schwerts], aber doch machte dich die Beharrlichkeit im Glauben zum Sieger vor Gott und den Menschen). Der Buchbinder wählte sicher bewusst dieses Werkzeug aus, um ausgerechnet ein Buch über die Märtyrer der Reformation aus der Feder des profiliert lutherischen Theologen Matthias Flacius Illyricus (Frankfurt 1573) zu verzieren (Kirch.G.fol.266).
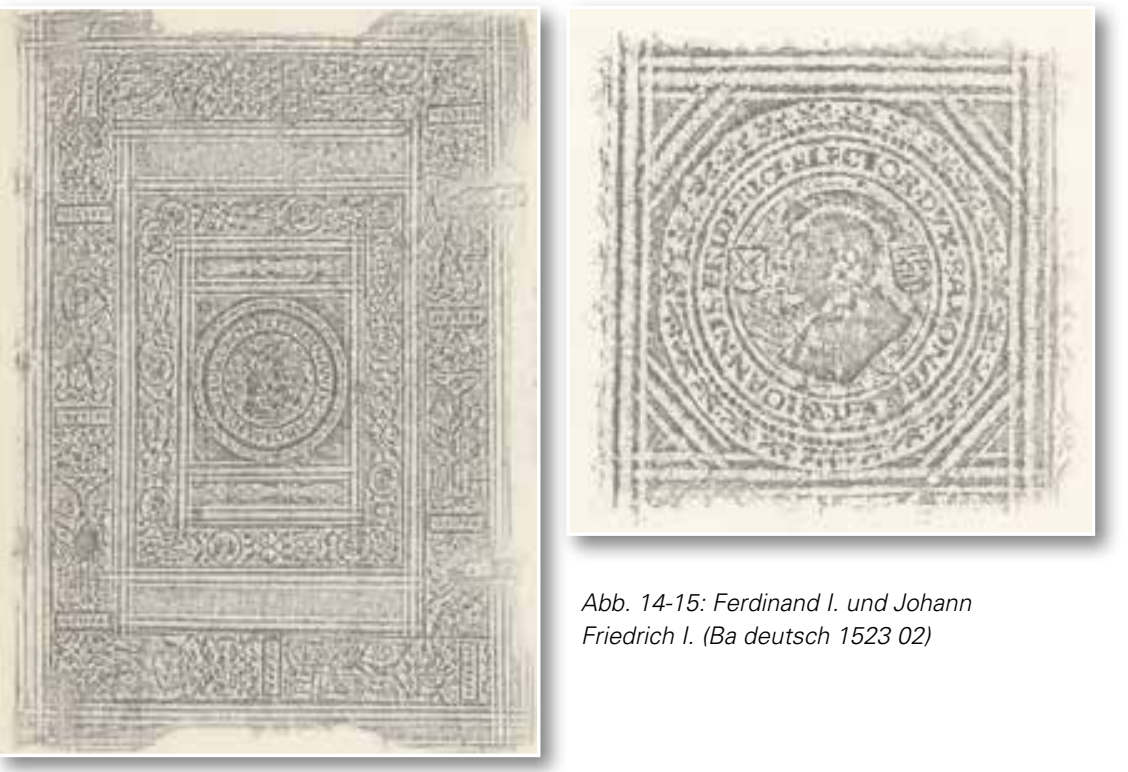

Abb. 14-15: Ferdinand I. und Johann Friedrich I. (Ba deutsch 1523 02)

Die Verzierung eines Einbands aus einer noch relativ frühen Phase der Reformation (1532) spiegelte die diplomatischen Hoffnungen der protestantischen Stände wider (Ba deutsch 1523 02). Auf dem Rückdeckel wurde Johann Friedrich I. von Sachsen abgebildet, auf dem Vorderdeckel jedoch nicht der amtierende römisch-deutsche Kaiser Karl V., sondern dessen späterer Nachfolger Ferdinand I. (1503-1564). Ferdinand hatte sich nämlich schon früh für eine konfessionelle Realpolitik und eine Duldung der Reformation ausgesprochen. Mit seiner Position auf dem Vorderdeckel einer Teilausgabe der Lutherbibel ging der Appell zu einer pragmatischen Kirchenpolitik auf Reichsebene einher. 


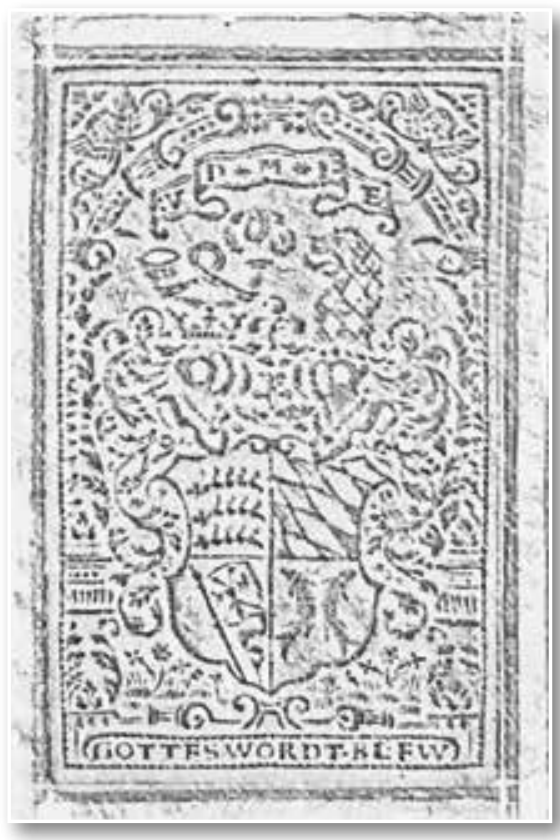

38

Abb. 16-17: Wappen und

Jael-Platte (Theol.fol.233-4)

\section{Indirekte motivische Rezeption der Reformation: Wappen}

Das altwürttembergische Kloster Alpirsbach wurde im Zuge der Reformation aufgehoben und als evangelische Schule weitergeführt. Mit der Einbandgestaltung einer wohl auch für den Unterricht verwendeten Ausgabe der Werke des württembergischen Reformators Johannes Brenz (Tübingen 1576-1590) (Theol.fol.233-3 bis -7) wollte der Stuttgarter Buchbinder Jakob Schedel der konfessionellen und regionalen Selbstvergewisserung dienen. Für den Vorderdeckel wurde eine Platte mit dem württembergischen Wappen und dem Landesmotto in ausgeschriebener und abgekürzter lateinischer Form verwendet (VDMIE [Verbum Domini manet in (a)eternum] / Gottes wordt blew [Gottes Wort bleibt in Ewigkeit]). Die Situation bleibender Bedrohung und Verteidigung der Reformation brachte Jakob Schedel für den vierten Band - durch die Kombination auf dem Einband in territorialer Zuspitzung - zum Ausdruck durch die Gestaltung des Rückdeckels. Die mutige Israelitin Jael, die dem feindlichen Feldherrn im Schlaf einen Zeltpflock durch die Schläfen trieb (Richter 4,21), wird mit dem Schwert und einem Heerlager im Hintergrund dargestellt. Der Textzusatz bezieht sich auf das Siegeslied der Debora (Richter 5,31) ("Sic pereant Omnes inimici tui domine judicum" = So sollen umkommen, Herr, alle deine Feinde!).
Tendenziell begegnen Wappen von Territorien in Verbindung mit theologischen Textzusätzen erst in der Spätphase der Reformation und der Zeit danach. In den frühen Jahren der Reformation waren unmittelbar theologische Themen mit

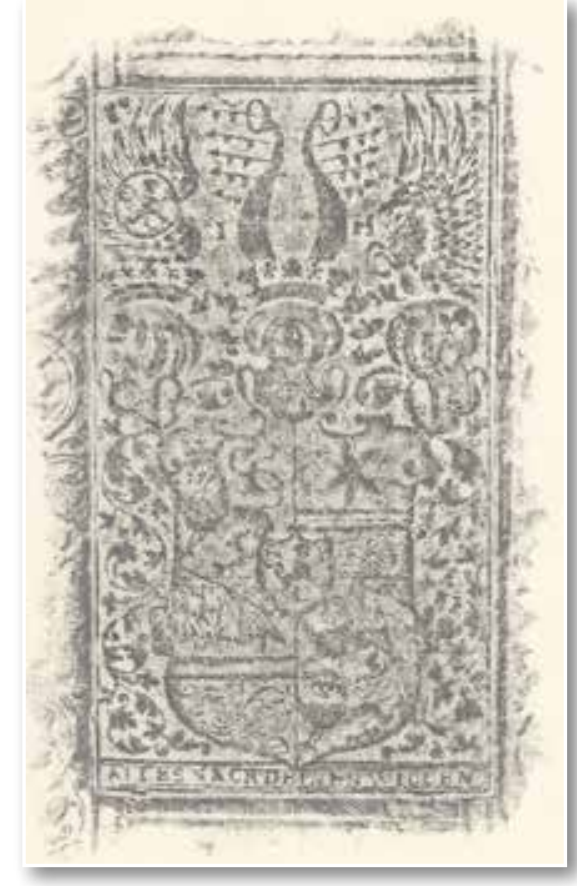

Fokussierungen zur Abgrenzung wichtig, dann auch die Reformatoren-Bildnisse. Nach Etablierung der Reformation in bestimmten Gebieten Deutschlands ging es um Bewahrung des Erreichten und darum, sich der Verknüpfung von regionaler und konfessioneller Identität sichtbar zu vergewissern. Das galt auch für die Heiratspolitik der Fürsten, bei der die konfessionelle Zuordnung der Sprösslinge einer Herrscherfamilie eine große Rolle spielte. So wurde in der württembergischen Werkstatt Georg Humes ein Psalmen-Kommentar mit einem Allianz- 
Wappen-Einband versehen (Theol.fol.1153). Die Zuordnung der Wappen von Württemberg mit dem bekannten Landesmotto und von Hessen nahm Bezug auf Herzog Ludwig Friedrich aus der Nebenlinie Württemberg-Mömpelgard (1586-1631), der 1617 eine hessische Prinzessin geheiratet hatte. Das hessische Motto „Alles nach deinem Willen" entspricht der exklusiven Ausrichtung reformatorischer Theologie am Willen und Handeln Gottes.

\section{Kontextualisierung}

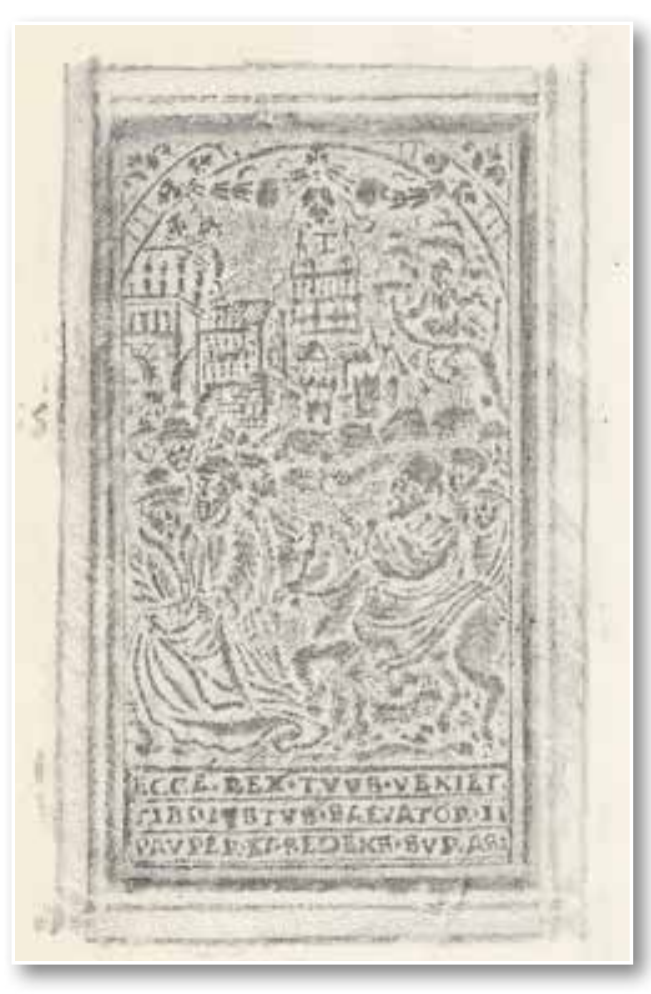

Abb. 20: Darstellung Meißens (Ba tschech.1579 01-1)

Die Lutherbibel sollte zum Leser so reden, „wie man auff dem marckt redt". 7 Es ging um Verständlichkeit. Die Menschen sollten begreifen, dass ihre existenziellen Grundanliegen dort verhandelt werden. Auf die Kunst übertragen konnte dies bedeuten, die dargestellten Motive in ihrer Gestaltung an den Lebensalltag der Adressaten anzupassen. Das „Für mich“ erschien plausibler, wenn die dargestellte Architektur, Landschaft oder auch Kleidung dem aus der eigenen Umgebung Gewohnten entsprach. Das galt umso mehr, wenn die Architektur nicht nur stilistisch den deutschen Kontext aufnahm, sondern ganz konkret bestimmte Gebäude aus dem Wohnort der Betrachter als Bildhintergrund zumindest vermutet werden konnten. Der wohl von Brosius Faust aus Meißen geprägte Vorderdeckel einer protestantischen Kralitzer Bibel (Ba tschech.1579 01-1 bis -6) stellt die Palmsonntagsszene mit dem Einzug Jesu in Jerusalem dar. Die Gebäude dieses Jerusalem könnten aber am Dom und Burgberg in Meißen orientiert sein. Zielgruppe waren vermutlich hussitische Flüchtlinge.

\section{Theologische Motive im engeren Sinn Rollen}

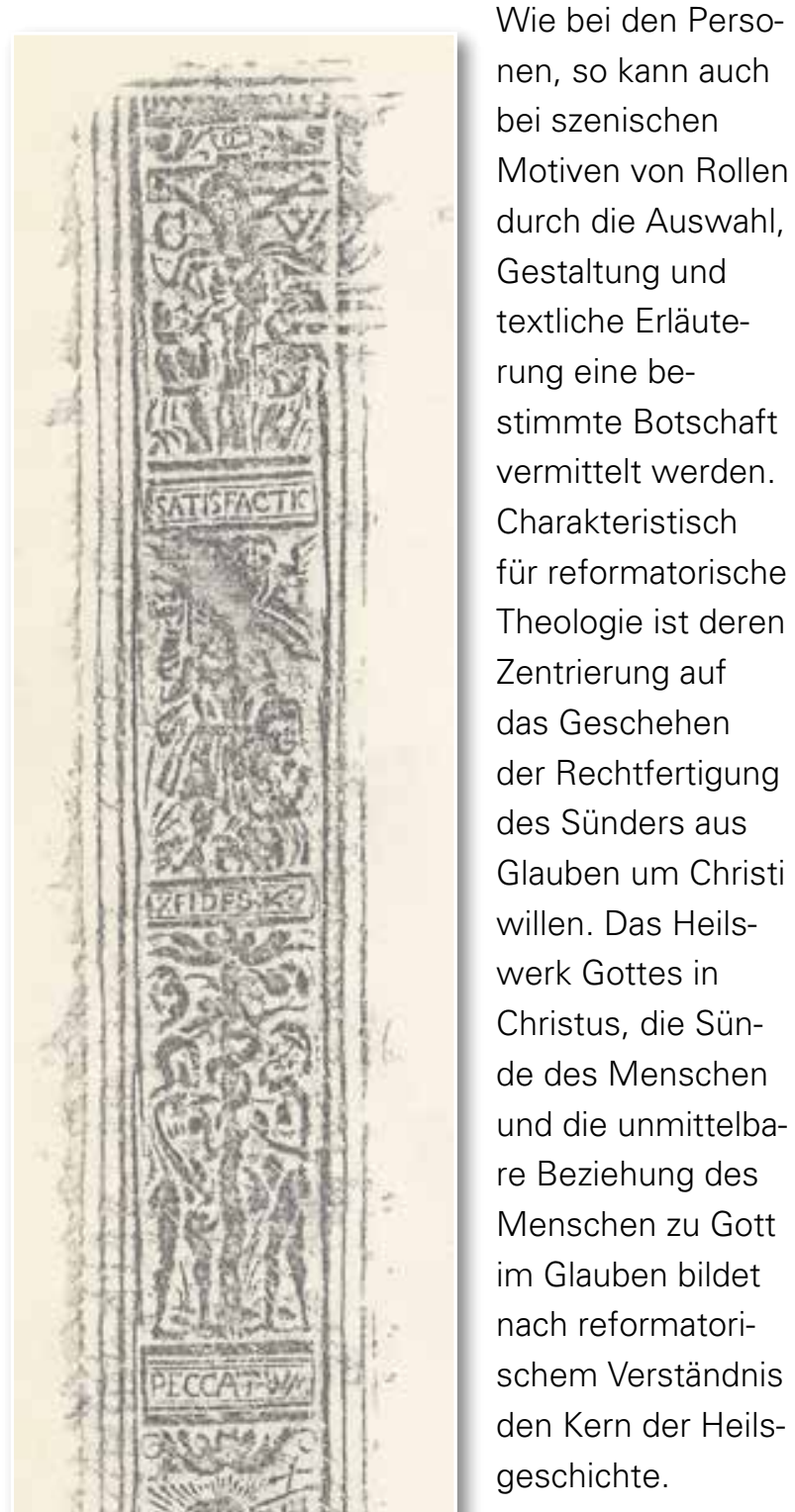

Eine Rolle des Monogrammisten C.W. auf einer Frankfurter Lutherbibel (Bb deutsch 1574 01) verband die Darstellung des Sündenfalls (peccatum), der Kreuzigung (satisfactio), der Auferstehung Christi (iustificatio) und der Opferung Isaaks durch Abraham (fides). 
Die Aussage sollte sein: Erst mit der Auferstehung Christi ist die Macht der Sünde gebrochen und erst mit einem Glauben analog zu Abraham wird das für den Einzelnen zur Wirklichkeit.

\section{Sammelbilder auf Platten}

\section{Symbole}

Statt zu einer ikonographischen Erweiterung konnte es umgekehrt jedoch auch zu einer symbolischen Komprimierung kommen (z.B. Theol. fol.1127). So stehen die persönlichen Wappen Luthers und Melanchthons ähnlich wie ihre Motti für zentrale Einsichten der Reformation. Weniger bekannt als die Lutherrose ist das in Anlehnung an Numeri 21,4-9 erstellte Wappen Melanchthons. Die Eherne Schlange, die Mose auf Geheiß Gottes anfertigte, sollte alle Israeliten vor Schlangen schützen, die sie mit Reue und Vertrauen auf die Verheißung Gottes anschauten. Dieses Geschehen wurde in Johannes 3,14-15 auf den gekreuzigten Christus bezogen. Indem Melanchthon die Eherne Schlange zu seinem Wappen wählte, stellte er die Erlösung des Sünders durch den Gekreuzigten ins Zentrum und erkannte zugleich die Heilige Schrift in ihrer Ganzheit aus Altem und Neuem Testament als Erkenntnisgrundlage an.

fol. 441 )

\section{Kombination von Werkzeugen}

produziert werden. Zwei komplexe Sammelbilder wurden gelegentlich auf dem Einband kombiniert und erweiterten dadurch den Aussagegehalt. So verband der Buchbinder einer Ausgabe des Augsburgischen Bekenntnisses, Frankfurt 1572 (Theol. fol.441), in einer Platte auf dem Vorderdeckel die Kreuzigung und Auferstehung Christi mit Johannes dem Täufer, der auf Christus deutet, und vermutlich Adam, der die Menschheit vertritt. ${ }^{8}$ Die Platte des Rückdeckels veranschaulicht die Ausgangslage, für die das auf dem Vorderdeckel dargestellte Geschehen eine Lösung herbeiführen soll: Sündenfall des Menschen, Gerichtsverfallenheit angesichts der Gebote Gottes (Mose mit Gesetzestafeln) und der drohenden Verdammnis in der Hölle, die Aufrichtung der Ehernen Schlange als temporärer, noch nicht universaler Gnadenerweis Gottes. Der Textzusatz spielt auf den Bußruf Jesu an (Lukas 13,5: „Wenn ihr nicht Buße tut, werdet ihr alle auch so umkommen") und verknüpft über das Thema Umkehr diese Platte mit dem Vorderdeckel, auf dem Johannes der Täufer als über sich hinaus weisender Bußprediger dargestellt ist.
Häufiger als in sich komplexe Werkzeugmotive war die Kombination von Werkzeugen mit in sich homogener strukturierten Motiven. Im Zentrum reformatorischer Theologie standen die Kreuzigung und Auferstehung Christi, durch die der Zusammenhang von Sünde und Tod durchbrochen wurde. Für den Einzelnen wirksam wurde dies

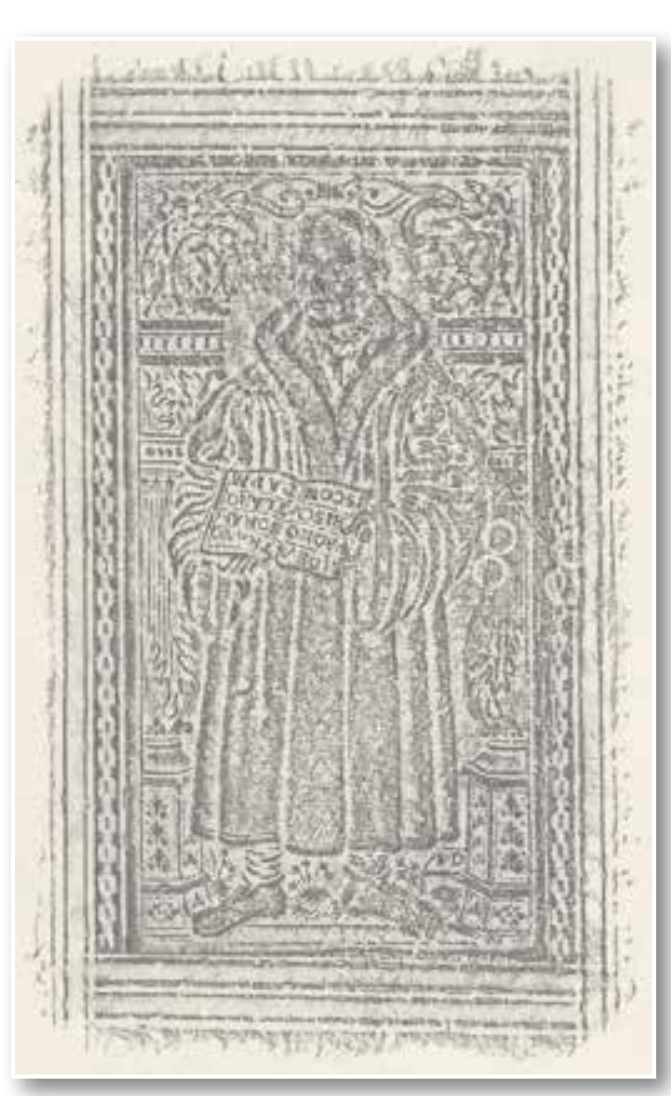

Abb. 24: Melanchthons Wappen (Theol.fol.1127) 
nach reformatorischem Verständnis durch den Glauben. Die bildliche Verarbeitung, gerade auch in der Bewegung von dem einen zum anderen Bild, sollte zum Entstehen und Bestehen des Glaubens beitragen.
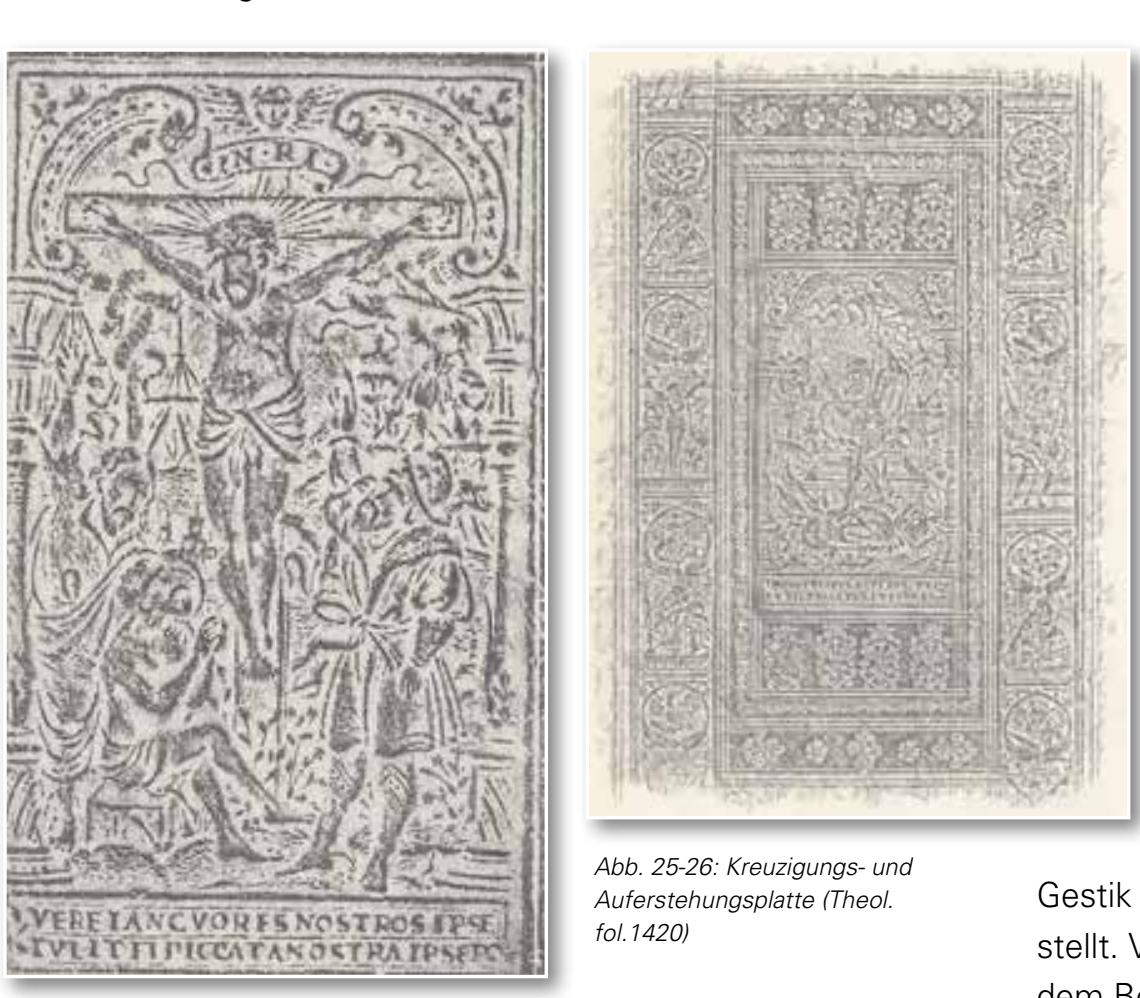

Abb. 25-26: Kreuzigungs- und Auferstehungsplatte (Theol. fol. 1420)

Der Einband einer Werkausgabe des dezidiert lutherischen Theologen Urbanus Rhegius (14891541), Frankfurt 1577 (Theol.fol.1420), weist diese Kombination einer Kreuzigungs- und Auferstehungsplatte auf. Der Tod wird auf der Auferstehungsplatte als Ungeheuer dargestellt, was auf den Teufel als dritte der von Luther so genannten Verderbensmächte hindeutet. Der Dresdener Buchbinder Brosius Faust umrahmte die Platten mit einer Rolle, auf der neben der Kreuzigung und Auferstehung auch Petrus und Paulus sowie die Evangelistensymbole zu sehen sind. Diese Zusammenstellung sollte im Sinne Luthers aussagen: Das Heilsgeschehen ist zugänglich über das Wort der Evangelien und neutestamentlichen Briefe. Das Heil kommt allein durch Christus, geschieht allein aus Gnade, ist inhaltlich und formal zugänglich allein über das Wort Gottes und wird wirksam allein im Glauben. Auf buchkünstlerische Weise wurde der innere Zusammenhang des vierfachen "Allein" der Reformation veranschaulicht.
Abb. 27-28: Salvator und

Sündenfall (B deutsch 1544 01)

Auf dem Einband einer Wittenberger Ausgabe der PsalmenÜbersetzung Luthers ( $B$ deutsch 1544 01) wurde Christus als Heiland der Welt

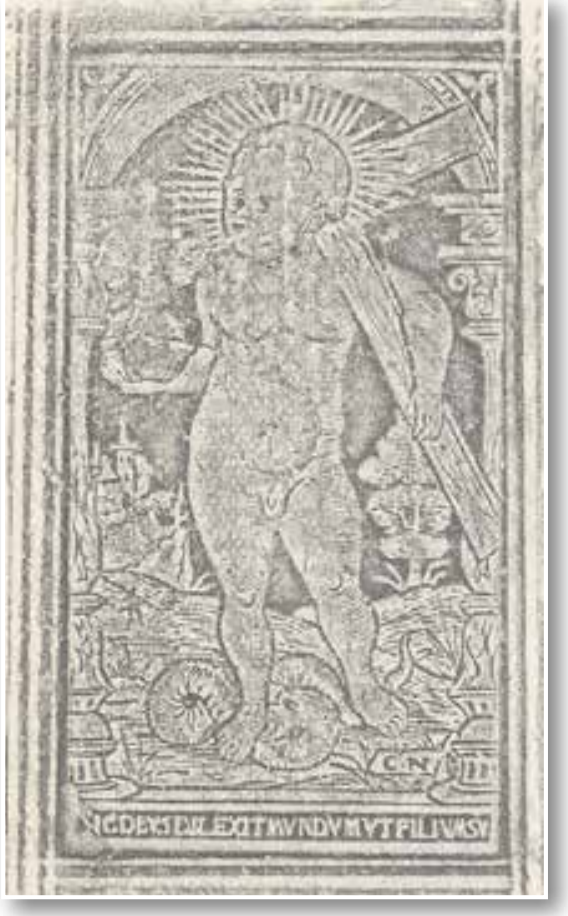
(Salvator) nicht wie sonst üblich mit der Körperhaltung und Gestik des Siegers dargestellt. Vielmehr bietet sich dem Betrachter der Salvator als Christuskind mit den Attributen Kreuz und Weltkugel, dabei stehend auf einer Schlange und mit einer Stadt im Hintergrund. Luther betonte stets, dass die Allmacht Gottes gerade in seiner Selbsterniedrigung

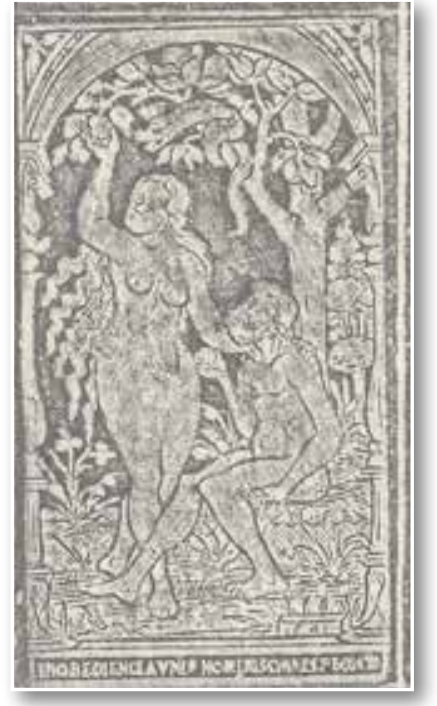
in der Geburt Christi und am Kreuz zum Ausdruck kommt. Reformatorische Theologie war eine "Theologie des Kreuzes" (theologia crucis), die gegen den Augenschein die Wirklichkeit des Sieges Gottes über die Verderbensmächte ebenso glaubt wie die Wirklichkeit der Kirche. Die Schlange und die Stadt auf der ersten Platte verknüpfen diese mit der Platte auf dem Rückdeckel. Dort geht um die Wirksamkeit des Bösen unter den Menschen (Sündenfall und Erbsünde). Die Erkenntnis der Sünde und das Bekenntnis des Sünderseins ist die negative Voraussetzung des Heilswirkens Gottes und gehörte sozusagen als Hintergrund oder Untergrund wie der Rückdeckel zum Vorderdeckel dazu.

Aus der Wittenberger Werkstatt des Thomas Reuter stammt ein Einband um ein theologisches Lexikon 


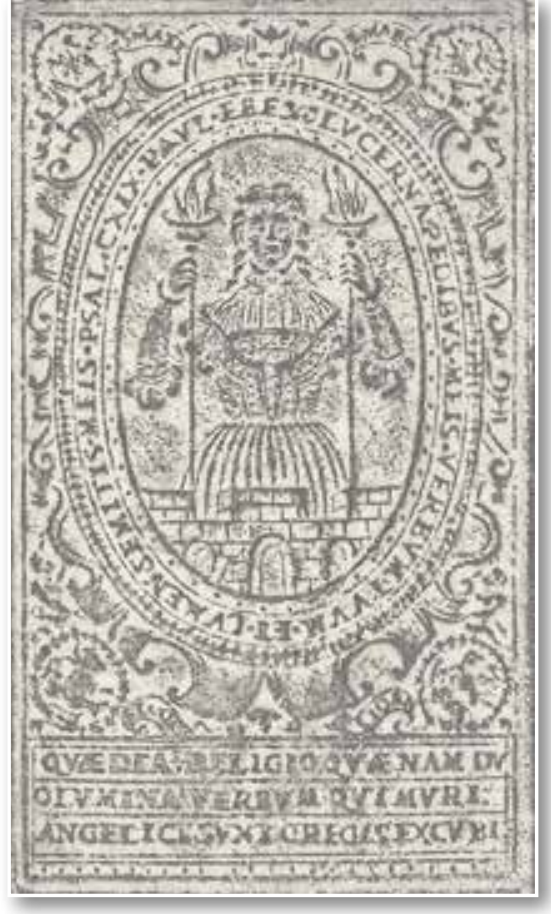

des norddeutschen Theologen David Chytraeus, Wittenberg 1578 (Theol. oct.3116). Der Vorderdeckel weist eine Platte mit der personifizierten Religio, einer Frauenfigur mit zwei Fackeln, auf. Das Mitteloval wird gerahmt von einem Schriftband, das in lateinischer Form den Beginn von Psalm 119, 105 zitiert („Dein Wort ist meines Fußes

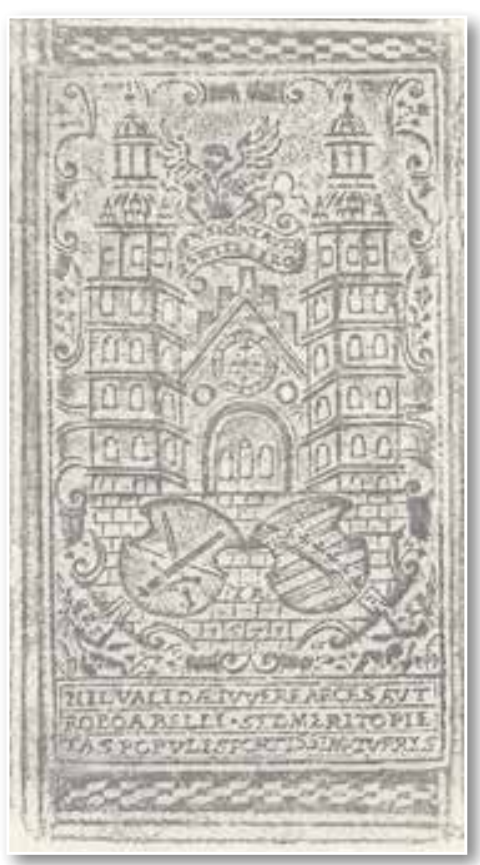

Abb. 29-30: Wort Gottes (Theol.oct.3116)

Leuchte und ein Licht auf meinem Wege"). Zusammen genommen sollte dies andeuten, dass Glaube vornehmlich auf dem Wort Gottes gründet, dem Wort hierbei eine Orientierungsfunktion auf dem Weg des Lebens zukommt. Präzisiert wurde dies noch durch das Textfeld in einem Schriftbalken unter dem Mitteloval: „Qvae Dea? Religio. Qvae nam dvo lumina $=$ Verbvm. Qvi mvri? Angelici svnt gregis excvbi" (= Welche Göttin? Religio. Welches sind denn die Lichter: das Wort. Welches sind die Mauern? Die himmlische (Heer)schar / Herde, die wacht). Auf dem Rückdeckel wurde eine Platte mit der Stadtkirche und dem Wappen Wittenbergs aufgeprägt. Der Einband insgesamt sollte andeuten, dass Wittenberg als Kulminationspunkt der Reformation im Sinne einer Wort-Gottes-Bewegung verstanden wurde.

\section{Der Vergleichspunkt: Katholische Einbandverzierung}

An Einbänden katholischer Buchbinder lassen sich seltener und später konfessionelle Akzentuierungen

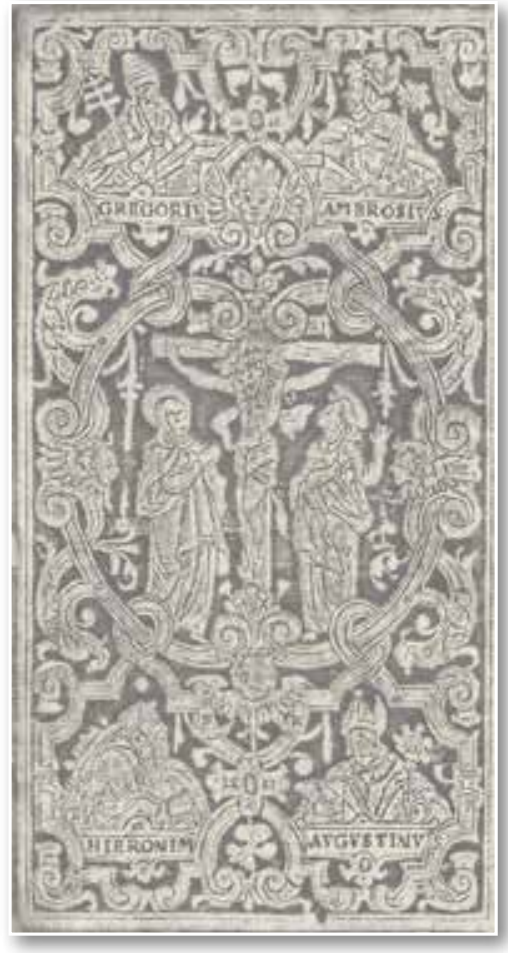

der Ikonographie feststellen als im Einflussbereich der Reformation. Exemplarisch ist ein aus dem Kloster Weingarten stammendes Exemplar eines 1586 in Venedig gedruckten Kirchengeschichtslehrbuches (Kirch.G.fol.802).

Der Leipziger Buchbinder Fabian Kleinschmidt prägte dem Vorderdeckel die Verkündigung an Maria und die vier Evangelisten auf.

Der Rückdeckel zeigt die Kreuzigung Christi nicht wie auf reformatorischen Platten mit Mose, Johannes dem Täufer (und Adam), um den Zusammenhang von Verheißung und Erfüllung aufzuzeigen. Vielmehr wählte Kleinschmidt - nahe am biblischen Text! - Maria und den Jünger Johannes als Figuren unter dem Kreuz aus. Zusammen mit dem Vorderdeckel wurde dadurch die Rolle Marias stark betont. Die Eckmedaillons stellen die vier wichtigsten lateinischen Kirchenväter dar: Gregor der Große, Ambrosius,
Abb. 31-32: Maria und Kirchenväter (Kirch.G.fol.802)

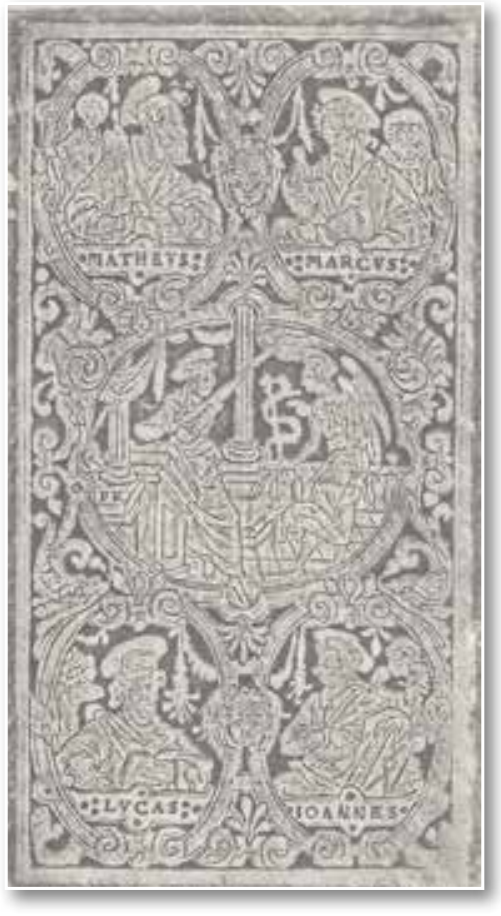
Hieronymus, Augustinus.

Das Zueinander zu den Evangelisten greift das Zusammenwirken von Schrift und Tradition auf. Wie Maria stellvertretend für die vermittelnden Instanzen des Heilswegs steht, so soll die Möglichkeit eines unmittelbaren Zugangs zur Bibel problematisiert werden. Die Botschaft heißt: keine Bibelauslegung ohne Rückbezug auf und Einklang mit der theologischen Lehrtradition.

Christian Herrmann 